\title{
Sustainable transport development and passenger transport demand in Poland
}

\author{
Tomasz Szczuraszek*, and Jacek Chmielewski \\ University of Science and Technology, Department of Traffic Engineering and Transport, \\ 85-796 Bydgoszcz, Kaliskiego 7, Poland
}

\begin{abstract}
Summary. Development of sustainable transportation is a process which involves promoting efficient transport systems meeting social expectations, while reducing any sub-optimal or harmful effects on public health, natural environment, economy and urban planning. Therefore, in the case of passenger transport, the most effective measure to achieve sustainable transport development is to maximize the share of public transport. This paper analyses trends in changes of demand for passenger transport in European Union Member States, in Poland and in Kujawsko-Pomorskie province, including in urban and non-urban areas. Based on collected data and extensive transport-related research of the authors, including surveys of residents, the most important conditions have been defined which affect passenger transport demand in Kujawsko-Pomorskie province, and a forecast has been attempted of the demand in three different scenarios of economic development (optimistic, stable and regressive) for various years. The projected public transport demand has been established on the basis of simulations using a proprietary transport model. Results of these calculations revealed surprising conclusions which indicate unfavourable trends in changes of the analysed demand and insignificant differences in projected transport needs, regardless of the selected economic development option for the country and the province.
\end{abstract}

\section{Introduction}

Respecting the principle of sustainable development in socio-economic development policies of a country involves the need to integrate economic and social objectives with environmental objectives. In Poland, this applies mainly to the transportation system, energy sector, industries, municipal services, as well as tourism and recreation - sectors which put the most pressure on the environment through direct or indirect utilisation of its resources and generation of waste and harmful physical effects.

Curbing noise emissions to the environment and preventing air pollution are just two main goals pursued by a majority of countries worldwide [1]. Continuous growth of road traffic causing increased emissions of both noise and pollution [2] makes a lot of countries, including Poland, stimulate transport development by providing sustainable development conditions. Sustainable transport development [3] is understood as a process which

\footnotetext{
${ }^{*}$ Corresponding author: zikwb@utp.edu.pl
} 
combines the promotion of efficient transportation, meeting social expectations, with the restriction of sub-optimal or even harmful influence of means of transport on public health, natural environment, economy and urban planning. Therefore, ensuring high competitiveness and appeal of public transport services, cycling and walking as alternatives to private transport (driving) should be the core principle of any policy of sustainable development of a transport system [5,6].

When pursuing sustainable transport development one should bear in mind that travelling in a private means of transport largely makes journeys independent of various negative external factors, ensures a favourable microclimate inside the vehicle and enables direct connections. It is one of the reasons why in Poland there has been a continuous increase in the number of car registrations in recent years, reaching approx. 6-7\% annually, and the country has one of the highest rates of growth in car trips in the EU, exceeding $3 \%$ per year, whereas the average EU ratio has dropped by $1.9 \%$ [7].

Recently, in the most developed economies of the European Union a clear increase in the number of trips by means of public transport has been observed, which is a consequence of continued deterioration of road traffic conditions despite investing huge amounts of money in road infrastructure. Insufficient capacity of the roads, streets and intersections in particular, relative to very big traffic flows downgrades the quality of travel and causes more and more congestions on an increasing portion of road networks, not only at rush hours. Without any other ways to reduce travel times, more and more people are switching from private car travel to public transport services in those countries, which promotes dynamic development of this transport sub-system. Most of the countries now have more developed forms of public transport subsystems than Poland, with a much higher standard of service and quality of travel (mainly railway), which make a genuine and attractive alternative to a car when choosing a means of transport.

In Poland, we have a quite well-developed and constantly developing basic road network, however the infrastructure and the means of public transport are still not sufficient and are often obsolete, particularly outside cities. The Polish society, not affected by the increased traffic congestion on the roads (with the exception of a few large cities) on the scale which is encountered in the developed countries of Western Europe, has no reasons to give up travelling in private vehicles in favour of public transport, especially as travelling by public transportation modes often takes twice as long and the comfort offered is significantly lower [8]. The more frequent choice of the car as a means of travel, compared to public transport, is also a result of the continuous increase in the wealth of Polish citizens and a continuous increase in the level of motorisation. Technological developments have made the car a readily available means of transport. Nowadays, owning a car is not such a big financial challenge for the Poles either.

Besides the level of motorisation of a society and traffic conditions on the road network, population density and demography (population, birth rate, migration balance and age structure) also have a significant impact on the frequency of public transport travel. In both these aspects, Poland also comes out less favourably in comparison to the developed countries of the EU [7].

The development of public transport is much easier in the case of areas with high population density, including in particular such areas where a considerable part of the population is less affluent, and where there is a large number of travel origins and destinations. These areas are mainly characterised by a greater demand for such transport services. Considering that there is a significant density of population and travel origins and destinations in European agglomerations, conurbations and metropolitan areas, there is also a high density of transport networks, including public transport services. More difficult conditions for the development of public transport are found in areas with low to medium population density (especially in those inhabited by highly-motorised people, such as in a 
number of Polish provinces), which results from a low number of likely travellers in this transport sub-system. These areas are not only hardly attractive from the point of view of public transport, but also offer little potential for socio-economic growth. It is noteworthy that fast-growing passenger services in the EU are becoming attractive mainly in major cities or metropolitan areas or in connection with them, where there is a very high population density. In Poland, nearly $40 \%$ of the citizens live in rural areas with a very low population density, whereas in the developed countries of the EU the equivalent figure is only $26 \%$. In the case of large Polish cities, the population density is also relatively low. It is much different from the population density of many European cities - for example, Bydgoszcz has a three times lower population than such cities as Odessa, Naples and Milan (which are even smaller in terms of area) and more than eight times lower than such cities as Barcelona and Paris.

As a consequence of the above-mentioned conditions, for many years in Poland an increase in the intensity of vehicle traffic has been observed, accompanied by a steady decrease in the share of public transport by land.

The aim of this paper is to present, using an example of a selected area of the country, a detailed analysis of the conditions and possibilities of increasing the share of public transport in passenger traffic and thus creating conditions for sustainable development of transport in Poland. The central part of the Kujawsko-Pomorskie Province (the so-called 'Partnership Area') was selected for analysis, as it represents - in terms of transport and spatial development - most areas of the country.

The Partnership Area comprises two cities with district (poviat) rights and a few communes and municipalities making up the functional areas of the cities. The area is therefore formed by proper cities being the most prominent cities of the province: Bydgoszcz (360,000 inhabitants) - the capital city, and Torun (190,000 inhabitants), functionally interlinked, and by the communes of Bydgoszcz District, Torun District and neighbouring municipalities and communes of the two districts. The Partnership Area is located in the north-western part of Poland, and in the central-western part of the Kujawsko-Pomorskie province.

\section{Description of the research and analysis}

The most important tools used in the analysis were simulation transport models developed by the authors, because a professional approach to such analyses requires the use of appropriate IT solutions. This is due to the complexity of transport processes, their considerable variability over time and the influence of a great number of factors, such as spatial planning, external and internal conditions, the arrangement and properties of individual transport networks, travel behaviours of the residents, including their preferences, demography, traffic conditions within the road network etc. The developed transport models enable simulation calculations to reproduce both present and possible future transport processes in the analysed area, including the size of passenger flows in different variants of investment and non-investment activities, which also includes actions intended to bring social and economic effects, and the state of the environment.

Twelve transport forecasting models were developed for the purpose of the analysis, covering [8]:

a) Two forecast reference years:

- The year 2020,

- The year 2030,

b)Three economic development scenarios for the Partnership Area and the country:

- Optimistic (developmental),

- Balanced (stabilised), 
- Passive (regressive),

c) Two transport operation intervals:

- $24 \mathrm{~h}$,

- Morning rush hour (from 7.00 to 8.00 a.m.).

As it was in the case of the transport model of the Partnership Area for the current state, models for individual forecast periods were developed using the German VISUM software environment.

In order to develop the transport models, a few hundred thousand data items were collected and coded into appropriate databases to provide a detailed description of the whole Partnership Area (including every building) and its transport networks. Moreover, a great number of transport studies were conducted, including analyses of the current situation and projected changes in key processes affecting transportation. Many archival results of studies into road traffic, functioning of public transport and travel behaviours of the inhabitants of the Partnership Area were also used in the development of the transport models.

The transport-related studies comprised:

- Surveys carried out among residents of the cities, municipalities and communes covered in the analysis, as well as among the managements of economic zones, the staff of large manufacturing facilities, service providers and commercial enterprises, and members of transport associations; about 16,500 people were subject to the surveys altogether,

- Studies of the characteristics of road traffic:

- Comprehensive measurements of the traffic volumes and their types on all roads to Bydgoszcz and Torun, and to the seats of the municipalities (the counts were taken for 24 hours on a weekday),

- Establishment of the occupancy of the means of public transport,

- In selected profiles of the roads (in the same locations in which the comprehensive traffic volume counts were performed plus wherever the profiles were intersected by railways),

- Daily measurements of the occupancy of railway transport at all train stations within the Partnership Area,

- Measurements of the occupancy of suburban and regional bus services at all bus stations and major transfer points and bus stops of the public transport lines in the cities and seats of the municipalities and communes.

\section{Analysis of the factors stimulating sustainable transport development in the analysed area of the country}

\subsection{Predicted changes in demography, population structure and density in the Partnership Area}

One of the most important factors affecting the development of transport in an area is the population number and the structure of the population by age and type. All of these factors have a major influence on the potential demand for transport and have an effect on the type of means of transport used in travel.

There are more than 800,000 residents living in the Partnership Area, of which:

- $69.5 \%$ live in the largest cities, i.e. Bydgoszcz and Toruń,

- $11.2 \%$ live in the neighbouring municipalities and communes,

- $8.6 \%$ live in small towns, 
- $\quad 10.7 \%$ live in rural areas.

According to the demographic forecast, the population number in the Partnership Area, in the balanced scenario of economic development (the most likely), will have dropped by approx. 25,800 by 2030 , whereas in the passive scenario - by 12,300 . Only the optimistic scenario provides for the possibility of maintaining a stable number of inhabitants. The most unfavourable situation is expected in Bydgoszcz, as in the analysed time frame regardless of the scenario the population will decrease by 25.7 to 36.5 thousand. A similar forecast applies to Torun, where the expected loss of population ranges from 9.1 to 15.5 thousand, depending on the scenario of economic development. A relatively solid situation in terms of population numbers is expected in other, smaller towns in the Partnership Area. On the other hand, an increase by 2030 is predicted in the neighbouring communes of Bydgoszcz and Toruń, which is a major consequence of the so-called urban sprawl occurring in the two cities, and the rural areas should witness a growth in population (from about 8,000 to about 14,000 ).

The predicted demographic changes concerning the population numbers and the residence structure create the conditions for inhibiting the substantial growth rate of car traffic, but they also contribute to the loss of passengers using public transport. It is particularly vital for Bydgoszcz and Toruń, where the population will be the most sever and where the conditions for car traffic are already the most difficult in the whole Partnership Area. On the other hand, the slight increase in the number of inhabitants of the neighbouring communes of Bydgoszcz and Torun and in rural areas, expected in the coming years, will not have a material influence on the potential increase in the number of public transport users, for example, due to a high level of motorisation of the residents in these areas.

Of all the inhabitants of the Partnership Area, people aged 25-29 are the biggest group $(47.7 \%)$, followed by people over 60 years of age (about $22 \%$ ). The smallest groups are young people aged 10-24 (about 15.4\%) and children under 10 (about 10\%). Such an age structure of the local residents is unfavourable from the point of view of demand for public transport services, because - according to studies carried out by the authors [8] - in Kujawsko-Pomorskie province this type of transport is used mainly by young people who make up nearly $70 \%$ of all passengers. Unfortunately, the demographic forecasts for all the assumed scenarios of economic development indicate that this trend will continue as we are dealing with evident ageing of the population living in the Partnership Area.

Another negative phenomenon which adversely affects not only the development of the whole transport system, but also the economic growth of the region, is an evident decline in the number of the working-age population (people aged 18-69) including the employed.

The population density of the two largest cities of the Area is relatively low as compared to other European cities; it is getting lower and this trend is not expected to reverse. However, the predicted increase in the population density in the other parts of the Partnership Area, as already indicated, will not have a significant influence on the potential increase in the number of passengers using public transport.

\subsection{Change of the motorisation rate in the Partnership Area}

The most unfavourable factor affecting sustainable development of transport in the Partnership Area is the steady growth of the motorisation rate in this area, continuing since the political system changed in Poland (boosted after Poland became a member of the European Union). The number of vehicles doubled between 2000 and 2014. At the same time, the dynamics of car ownership among individual social groups was very high. These trends will hardly change in the coming years, although that will largely depend on the 
actual scenario of economic development. It should be noted that the motorisation rate of the residents of the Partnership Area is very high at present.

Surveys conducted by the authors among residents of the Kujawsko-Pomorskie province revealed that owning a car has a huge impact on the degree of use of public transports. It was found that even if people do not have a car, only $80 \%$ of them use a means of public transport, whereas the rest travel by car as passengers.

A very large share of the passengers relying on public transport do not have a car: $82 \%$ of the people using bus services and $56 \%$ of railway passengers. About $40 \%$ of all public transport users do not have a driving licence, either (about $63 \%$ of bus passengers and about $41 \%$ in the railway transport). Almost $60 \%$ of the surveyed public transport passengers expressed their preference for the car if they had a driving licence, a car and were capable of driving (i.e. had no physical disability making it difficult or impossible).

In the Partnership Area, individual transport is a comfortable means of travel and ensures acceptable travel times even at the time of increased traffic volumes and - in most cases - the least number of trips, as the car enables door-to-door travel. The only weakness of this transport mode is a higher cost of travel compared to public transport services.

It must be stressed that the road network within the Partnership Area provides relatively good conditions for travelling by car, given the current traffic volume, although the expressway network is still underdeveloped. The road traffic volume and the low capacity utilisation of the roads in the region encourage the residents to use individual transport, either as drivers or passengers. Even in the largest urban areas of the Partnership (Bydgoszcz and Toruń) the observed level of congestion on the roads is not high enough to make drivers change their preference of the transport mode. This is evident, for example, in the year-on-year decrease of the number of passengers in the urban transport system of Bydgoszcz while the traffic volume increases. It is worth mentioning here again that both cities will see a decline in the number of inhabitants and a further development of the local road infrastructure, which will further improve the road traffic conditions and thus reinforce the development of individual car transport.

Figure 1 presents the degree of use of different transport modes in non-walking and non-cycling trips within the Partnership Area, obtained from surveys. The results indicate a clear predominance of the car as the preferred means of transport (drivers and passengers) as compared with the public transport: in approx. $80 \%$ of the cases the car is used for trips where walking or cycling is not considered.

\section{Projected transport needs}

The transport needs were projected on the basis of detailed analyses for three scenarios of economic development of the country and the region: optimistic, balanced and passive, defined as follows:

- Optimistic (developmental) - characterised by dynamic development of the economy and a clear increase in the rate of motorisation and mobility of the residents (frequency of travel); it also assumes a substantial increase in the share of railway transport in all passenger cross-regional traffic in the country, and a moderate decrease in the number of long trips made by bus (according to the assumptions of the Ministry of Infrastructure and Construction); optimistic variants of the development of the national and provincial road network are also assumed along with the development of the national railway network infrastructure, mainly consisting in adaptation to high-speed rail; 


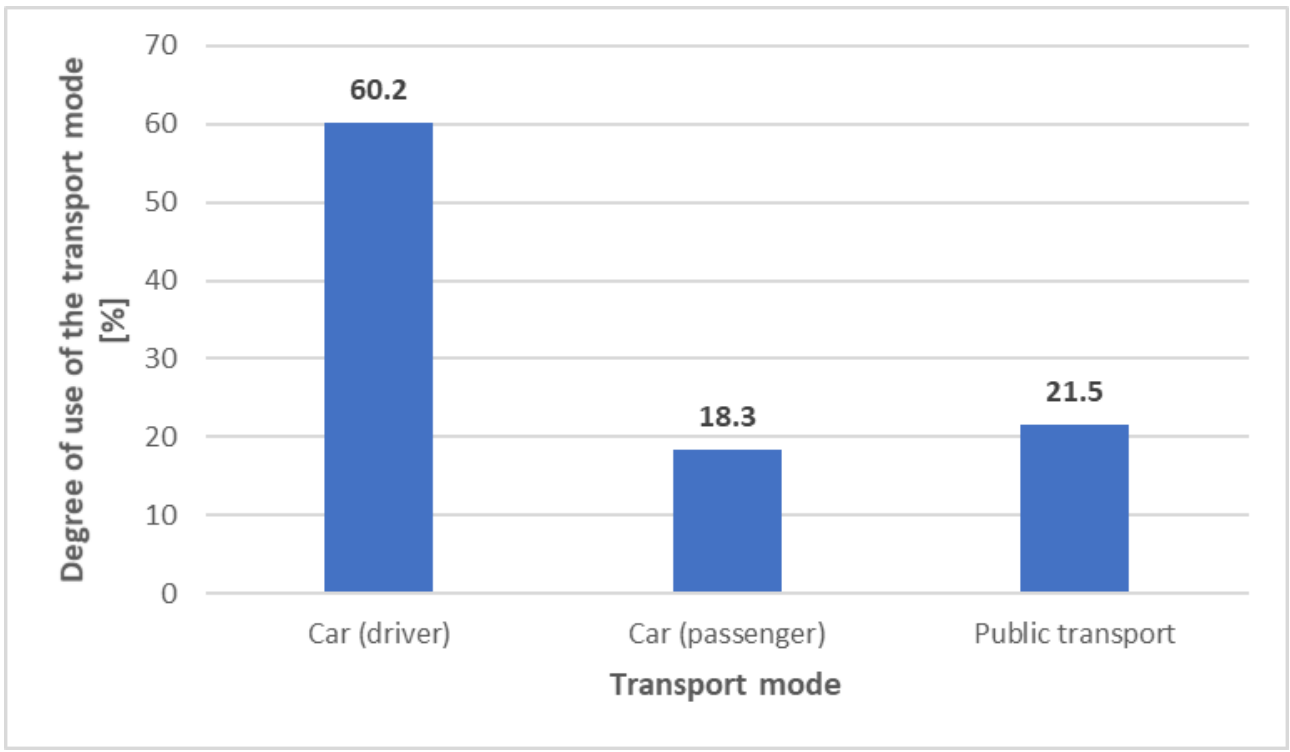

Figure 1 The degree of use of the different transport modes in non-walking and non-cycling trips by the residents of the Partnership Area in 2015

- $\quad$ Balanced (stabilised) - characterised by the maintenance of current trends in economy, motorisation rate and mobility of the residents; a slower pace of implementation of transport investment projects in Poland and the province is assumed as compared with the optimistic scenario;

- Passive (regressive) - characterised by the possibility of economic decline and the slowest development of transport investments in the country and the province, as well as a stabilisation of the motorisation and mobility rates.

The analysis of predicted transport needs for the reference years of 2020 and 2030 in the area under consideration was carried out by simulations using specifically-developed transport forecasting models. The level of projected demand for travel using particular transport modes among the residents of the analysed area is shown in Table 1.

The obtained results of the analyses show that by the year 2030 there will be a small increase in the number of trips made by the residents of the Partnership Area with the exception of the passive scenario of economic development, in which the expected total number of trips is expected to stabilise.

Both in the optimistic and the balance scenario an increase in the total number of trips by car is evident for the considered forecast reference years. This will certainly affect the overall traffic volumes on the road network of the Partnership Area. On the other hand, the passive scenario indicates a more-or-less constant number of trips by car, whereas the structure of the car travel will clearly change with a decrease in the share of driver trips due to a drop in the number of residents and cars. More people will travel by car as passengers, so the traffic volume on the regional roads should decrease.

In the case of public transport an increase in the number of trips - by as much as $25.5 \%$ - can only be expected if the optimistic scenario of economic development happened. Such a scenario is however unlikely. Unfortunately, in the other two cases the number of trips made by public transport will decline: by almost $13 \%$ by 2030 in the worst-case scenario, and by about $2.5 \%$ in the most likely one. This is undoubtedly bad for the development of public transport in the analysed area and - thus - for sustainable transport development as a whole. 
Table 1. Projected demand for travel by different transport modes among the residents of the analysed area

\begin{tabular}{|c|c|c|c|}
\hline \multicolumn{4}{|c|}{$\begin{array}{l}\text { Projected demand for travel by different transport modes among the residents of the } \\
\text { Partnership Area }\end{array}$} \\
\hline \multirow{2}{*}{ Transport mode } & \multicolumn{3}{|c|}{$\begin{array}{l}\text { Predicted number of trips in the given year } \\
\text { [in thousand trips } / 24 \mathrm{~h}]^{*}\end{array}$} \\
\hline & 2015 & 2020 & 2030 \\
\hline \multicolumn{4}{|c|}{ Optimistic scenario of economic development } \\
\hline Walking & $487.9(20.3 \%)$ & $541.5(21.0 \%)$ & $594.3(20.8 \%)$ \\
\hline Cycling & $240.0(9.9 \%)$ & $253.5(9.8 \%)$ & $278.3(9.7 \%)$ \\
\hline Public transport & $360.2(15.0 \%)$ & $387.0(15.0 \%)$ & $452.1(15.8 \%)$ \\
\hline Car (driver) & $1010.0(42.0 \%)$ & $1095.3(42.5 \%)$ & $1259.4(44.0 \%)$ \\
\hline Car (passenger) & $307.9(12.8 \%)$ & $299.0(11.6 \%)$ & $276.3(9.7 \%)$ \\
\hline$\sum$ & 2406.0 & 2576.3 & 2860.4 \\
\hline \multicolumn{4}{|c|}{ Balanced scenario of economic development } \\
\hline Walking & $487.9(20.3 \%)$ & $525.3(21.3 \%)$ & $546.0(21.3 \%)$ \\
\hline Cycling & $240.0(9.9 \%)$ & $247.3(10.0 \%)$ & $265.2(10.4 \%)$ \\
\hline Public transport & $360.2(15.0 \%)$ & $352.2(14.3 \%)$ & $351.1(13.7 \%)$ \\
\hline Car (driver) & $1010.0(42.0 \%)$ & $1030.7(41.8 \%)$ & $1086.5(42.4 \%)$ \\
\hline Car (passenger) & $307.9(12.8 \%)$ & $310.3(12.6 \%)$ & $310.8(12.1 \%)$ \\
\hline$\sum$ & 2406.0 & 2465.8 & 2559.6 \\
\hline \multicolumn{4}{|c|}{ Passive scenario of economic development } \\
\hline Walking & $487.9(20.3 \%)$ & $526.3(21.7 \%)$ & $538.6(22.2 \%)$ \\
\hline Cycling & $240.0(9.9 \%)$ & $248.5(10.2 \%)$ & $261.7(10.8 \%)$ \\
\hline Public transport & $360.2(15.0 \%)$ & $338.7(13.9 \%)$ & $314.9(13.0 \%)$ \\
\hline Car (driver) & $1010.0(42.0 \%)$ & $992.1(40.8 \%)$ & $959.0(39.6 \%)$ \\
\hline Car (passenger) & $307.9(12.8 \%)$ & $325.1(13.4 \%)$ & $349.7(14.4 \%)$ \\
\hline$\sum$ & 2406.0 & 2430.7 & 2423.9 \\
\hline
\end{tabular}

Regardless of the scenario of economic development the number of trips made on foot and by bike is expected to increase. Depending on the scenario, walking and cycling trips are predicted to increase by 2030 from $10.4 \%$ to nearly $22 \%$, and from $9.1 \%$ to $16 \%$, 
respectively. This is mainly related to the general trend of increased mobility of residents in the country and the growing fashion for cycling, especially for recreational purposes.

It should be underlined that the share of utilisation of public transport relative to the use of car may slightly increase only in the optimistic scenario of economic development: by about $0.2 \%$ by 2020 and about $1.2 \%$ by 2030 (see Table 1 ). In any other case a decrease should be expected, however not a substantial one (max. $2.1 \%$ ).

Table 2 presents the projected demand for freight related travel in the Partnership Area. This type of travel is expected to rise in all the economic development scenarios taken into consideration; naturally, in the case of the passive scenario the increase will be very small, but it may reach about $33 \%$ by 2030 in the optimistic option (about $34 \%$ for vans and about $31 \%$ for trucks).

Table 2. Projected demand for freight related travel in the Partnership Area

\begin{tabular}{|c|c|c|c|c|}
\hline \multicolumn{5}{|c|}{ Projected demand for freight transport in the Partnership Area } \\
\hline \multirow{2}{*}{ Transport mode } & \multirow{2}{*}{$\begin{array}{c}\text { Economic } \\
\text { development } \\
\text { scenario } \\
\end{array}$} & \multicolumn{3}{|c|}{ Predicted number of trips [in thousand trips $/ 24 \mathrm{~h}$ ] } \\
\hline & & 2015 & 2020 & 2030 \\
\hline \multirow{3}{*}{$\begin{array}{l}\text { Light goods } \\
\text { vehicles }\end{array}$} & Optimistic & \multirow{3}{*}{$273.0(60.2 \%)$} & 311.0 & 366.6 \\
\hline & Balanced & & 291.0 & 311.5 \\
\hline & Passive & & 273.5 & 273.8 \\
\hline \multirow{3}{*}{$\begin{array}{l}\text { Heavy goods } \\
\text { vehicles }\end{array}$} & Optimistic & \multirow{3}{*}{$180.7(39.8 \%)$} & 203.9 & 237.2 \\
\hline & Balanced & & 192.1 & 204.8 \\
\hline & Passive & & 181.8 & 182.4 \\
\hline \multirow{3}{*}{ Total } & Optimistic & \multirow{3}{*}{453.7} & 514.9 & 603.8 \\
\hline & Balanced & & 483.1 & 516.3 \\
\hline & Passive & & 455.3 & 456.2 \\
\hline
\end{tabular}

\section{Conclusions}

According to the forecasts, the significant increase of walking and cycling trips by 2030 should be considered as a positive aspect for achieving the sustainable transport development in the analysed area. Depending on the scenario of economic development, the increase in walking trips is expected to reach from $10.4 \%$ to nearly $22 \%$ by 2030 , and from $9.1 \%$ to $16 \%$ in the case of cycling. This is mainly related to general trends in the country, increasing mobility of the residents and the fashion for cycling, especially as a form of leisure activity. On the other hand, the negative factors inhibiting the process are the $2.5 \%$ decrease in the number of trips by public transport and the nearly $7.6 \%$ increase in the number of car trips (in the most probable, i.e. balanced development scenario). This translates into an average annual increase in traffic volumes of about $0.5 \%$ on the roads within the analysed area.

In order to improve the situation, at least to some extent, the following imperatives should be considered when planning further development of transport systems: 
1) Make public transport the preferred choice for the residents through:

a) Tariff integration among the operators of public transport;

b) Spatial and temporal integration of all systems and individual public transport services;

c) Integration of public transport with individual car transport (provision of park \& ride facilities) and the city bike-sharing systems;

d) Implementation of modern passenger information systems;

e) Improvement of the standard and features of all stops and stations;

f) Improvement of the standard and features of public transport modes;

g) Prioritization of public transport in road traffic systems (e.g. priority traffic control on intersections with traffic lights);

h) Assignment of independent traffic corridors for the means of public transport;

i) Reduction of vehicle traffic in crucial areas from the point of view of environmental protection.

2) Encourage cycling through the development of bike ways and lanes, including the development of city bike-sharing systems (in large and medium size cities).

3) Encourage ecological means of public and individual transportation.

4) Elimination of congestion spots on the road network which lead to tie-ups and traffic jams and thus to increased emission of noise and harmful substances to the environment.

5) Implementation and development of Intelligent Transport Systems (mainly in the two cities).

\section{References}

1. Vestreng V., Myhre G., Fagerli H., Reis S., Tarrason L., Twenty-five years of continuous sulphur dioxide emission reduction in Europe, Atmos. Chem. Phys., 7, 3663-3681, 2007

2. Choudhary A. Gokhale S.; Urban real-world driving traffic emissions during interruption and congestion; Transportation Research Part D: Transport and Environment, Volume 43, March 2016, Pages 59-70

3. Gudmundsson H., HiSje M., Sustainable development principles and their implications for transport, Ecological Economics 19 (1996) 269-282

4. Litman T., Burwell D., Issues in sustainable transportation, International Journal of Global Environmental Issues, Volume 6, Issue 4 (2006)

5. Urban Union: Cities of tomorrow. Challenges, vision, ways forward. European Commission, Directorate General for Regional Policy (2011)

6. A sustainable future for transport: Towards and integrated, technology - led and user friendly system. Commission of the European Communities. Brussels (2009)

7. European Commision: UE Transport in figures. Statistical Pocketbook 2016. Luxemburg (2016)

8. Study of the sustainable development of transport systems in the poviats of Bydgoszcz and Torun, with particular emphasis on the cities of Bydgoszcz and Torun. EEA Grants and Norway Grants project. Bydgoszcz (2016) 